\title{
ACCENT STRUCTURE VARIATION IN ADJECTIVES ENDING IN -OVYY
}

\author{
Aleksey A. Abyzov \\ Ivanovo State Polytechnic University, Ivanovo, Russia \\ Yuliya N. Zdorikova \\ Ivanovo State University of Chemistry and Technology, Ivanovo, Russia
}

\begin{abstract}
The paper focuses on the specificity of functioning of a group of adjectives ending in -ovyy that are differently accentuated in the modern Russian language. Based on the concept of indispensable link between the norm and its variation, a two-stage experiment has been conducted, the results of which make it possible to characterize the specificity of accent variants given in orthoepic dictionaries and used in speech by native speakers of the Russian language. Test group of adjectives ending in -ovyy are considered from the viewpoint of their accentuation in reference books, and a comparative analysis of accentual options of lexical items is carried out on the basis of three orthoepic dictionaries of the Russian language. Various ways of correlation between the adjective alternants in the context are identified: 1) equal; 2) basic /acceptable; 3) stylistically different; 4) semantically different. The main conclusions are drawn about the wide degree of accent variation types, and consequently, on the dynamics of the accent norm in the given test group of lexical items. Both cases of complete coincidence and inconsistency of alternants in the analyzed reference book sources are indicated. The observations over the peculiarities of functioning of the considered adjectives in the student discourse, obtained as a result of the analysis of the students' survey, are also systematized. In general, we may conclude that students observe the accent norms when using the mentioned lexical items in speech.
\end{abstract}

Key words: pronunciation, norm of pronunciation, language norm, variation, orthoepic dictionary, accentual word structure, students' discourse, the Russian language.

Citation. Abyzov A.A., Zdorikova Yu.N. Accent Structure Variation in Adjectives Ending in -ovyy. Vestnik Volgogradskogo gosudarstvennogo universiteta. Seriya 2, Yazykoznanie [Science Journal of Volgograd State University. Linguistics], 2018, vol. 17, no. 3, pp. 181-188. (in Russian). DOI: https://doi.org/10.15688/jvolsu2.2018.3.19

\section{ВАРИАТИВНОСТЬ АКЦЕНТНОЙ СТРУКТУРЫ СЛОВА (НА ПРИМЕРЕ ПРИЛАГАТЕЛЬНЫХ НА -ОВЫЙ)}

\section{Алексей Алексеевич Абызов}

Ивановский государственный политехнический университет, г. Иваново, Россия

\section{Юлия Николаевна Здорикова}

Ивановский государственный химико-технологический университет, г. Иваново, Россия

Аннотация. В статье приводятся наблюдения над особенностями функционирования в современном русском языке группы прилагательных на -овыци, имеющих разнообразные акцентные варианты. С опорой на положение о неразрывной связи языковой нормы и ее вариативности проведен двухэтапный эксперимент, результаты которого позволили охарактеризовать специфику отражения акцентных вариантов в орфоэпических словарях и речевой практике носителей русского языка. Рассмотрены словарные фиксации ударения в контрольной группе прилагательных на -овый, проведен сравнительный анализ акцентных вариантов 


\section{МАТЕРИАЛЫ И СООБЩЕНИЯ}

лексем по трем современным орфоэпическим словарям. Выявлены разные типы соотношения вариантов прилагательных на -овый: равноправные, основной / допустимый, различающиеся стилистически и по значению. Сделаны выводы о широкой степени вариативности акцентных типов слов и, как следствие, о подвижности акцентной нормы в контрольной группе лексем. Указаны случаи как полного, так и неполного совпадения вариантов в анализируемых словарных источниках. Систематизированы наблюдения над особенностями функционирования рассматриваемых прилагательных на -овый в студенческом дискурсе, полученные в ходе изучения результатов опроса студентов. Сделаны выводы о соблюдении акцентологических норм при использовании указанных лексем в речи студентов.

Ключевые слова: орфоэпия, орфоэпическая норма, языковая норма, вариативность, орфоэпический словарь, акцентная структура слова, речь студентов, русский язык.

Цитирование. Абызов А. А., Здорикова Ю. Н. Вариативность акцентной структуры слова (на примере прилагательных на -овый) // Вестник Волгоградского государственного университета. Серия 2, Языкознание. -2018. - Т. 17, № 3. - С. 181-188. - DOI: https://doi.org/10.15688/jvolsu2.2018.3.19

\section{Языковая норма и вариативность}

Современная орфоэпическая система русского литературного языка (как, впрочем, и любого другого живого языка) характеризуется наличием большого количества произносительных вариантов, что отражено в орфоэпических словарях (Горбачевич; Каленчук и др.; Орфоэпический словарь; Резниченко) и исследованиях (см., например: [Вербицкая, 2001; Костомаров, 2014]). В языкознании вариативность, или способность к постоянным изменениям, рассматривается в качестве одного из основных свойств любого естественного языка [Vishnevskaya, 2000], причем оно не является изолированным, а представляет собой способ «существования и функционирования всех без исключения единиц языка», обнаруживающий «специфические черты в пределах каждого уровня» [Солнцев, 1984, с. 31]. В этой связи центральными в исследованиях многих ученых-лингвистов в последнее время стали вопросы вариативности языковой нормы, прежде всего на фонетическом уровне.

По мнению многих исследователей, вариативность является следствием эволюции языка и связана с его историческим характером [Вербицкая, 2001, с. 26; Горбачевич, 1978, с. 3; Солнцев, 1984, с. 31]. Именно через варианты осуществляется развитие нормы [Едличка, 1976, с. 31], и при оценке нормативности необходимо учитывать все отклонения (варианты) [Вишневская, Абызов, 2016, с. 96]. Нередко «старый» вариант сосуществует с «новым» в течение определенного промежутка времени. Так, по утверждению К.С. Гор- бачевича, хронологическое соотношение «старый (традиционный) вариант - новый (входящий)» является основным внутренним отличием вариантов слова, а их распределение на оси времени - главным аспектом характеристики [Горбачевич, 1978, с. 206]. При этом «в языке, отрегулированном и узаконенном в качестве правильного, общего, можно видеть систему обязательных манифестаций - принятых единиц и правил их использования. Они рисуются одновременно как неподвижная данность и - за пределами непосредственного наблюдения - как процесс непрерывных точечных смен, по мере накопления которых возникают серьезные преобразования» [Костомаров, 2014, с. 16].

Являясь фундаментальным свойством языковой системы, вариативность присуща всем уровням языка. Исходя из их иерархии, лингвисты выделяют следующие классы вариантов: орфоэпические (фонетические: произносительные и акцентные), лексические, грамматические (морфологические: словоизменительные и словообразовательные, синтаксические), стилистические.

Каждый уровень при этом характеризуется разным проявлением вариативности. «Интересно, что язык не только в разные эпохи с разной скоростью развивается, но и в разных своих частях по-разному. Морфология, произношение, фонетика развиваются очень медленно. Мы даже говорим, что после Пушкина не произошло никаких особых изменений в русском языке, что это тот же язык. Но в лексике, в стилистике, отчасти в синтаксисе изменения, конечно, совершенно очевидны» [Встречи с Костомаровым..., 2015, с. 40]. При 
этом на фонетическом ярусе количество допустимых нормой вариантов больше, чем на других уровнях [Шахбагова, 1992, с. 57]. Кроме того, в области орфоэпии система «практически целиком определяет норму» [Петрова, 2013 , с. 84]. Поэтому в произношении есть понятие образца, идеала, который часто ориентирован на прошлое [Скворцов, 1980, с. 48].

В лингвистике существует проблема классификации вариантов на фонетическом уровне ввиду терминологических разногласий (один и тот же термин трактуется по-разному, за основу классификации берутся различные критерии). Наиболее полное определение орфоэпического варианта, на наш взгляд, приводится в работе Т.В. Левиной: под этим термином понимаются относительно регулярно воспроизводимые модификации звуковой и акцентной структур слова, существующие в пределах литературной нормы и характеризующиеся тождественностью значения [Левина, 2003, с. 57].

В орфоэпии различаются собственно фонетические (произносительные) и акцентные варианты. Если первый тип отражает особенности функционирования фонемной структуры слова, то второй - его акцентной структуры. Фонемная структура слова определяется количественным составом и последовательностью фонем, свойственным только данному слову в многообразии его морфологических видоизменений. Акцентная структура слова характеризуется количеством, качеством, взаиморасположением и степенью выделенности слогов в слове. При этом различия в степени ударения, последовательное распределение сильного и второстепенного ударения, различное количество ударений в слове создают акцентные типы слов [Левина, 2003, с. 57-58]. Иными словами, под акцентным типом слов понимаются особые структурные единицы фонетической системы языка, складывающиеся из различного количества ударений в слове и различий в проминантности слогов [Торсуев, 1977, c. 79-84]. Акцентная структура слова в пределах одного акцентного типа складывается из распределения ударений по слогам слова [Левина, 2003, с. 58]. В артикуляторном отношении акцентные структуры и типы представляют собой динамические стереотипы, прочно входящие в артикуляторную базу и характер- ные для фонетического строя языка [Торсуев, 1960, c. 49-50].

В целом акцентные варианты представляют собой, как правило, тождественные в плане содержания разновидности одного и того же слова с разной акцентной структурой.

В данной работе предложено описание словарной фиксации ударения в прилагательных на -овый и экспериментальных данных об их акцентологических вариантах в дискурсе студентов. Таким образом в научный оборот вводится новый материал, что определяет новизну исследования. Его актуальность обусловлена слабой изученностью вариативности орфоэпической нормы современного русского языка, в частности вариантов акцентуации в названной группе лексем.

\section{Методика проведения эксперимента}

В современном русском языке вариативность ударения наблюдается и в прилагательных, заканчивающихся на -овый, таких как мuтинговый, лозунговый, поисковый и мн. др. Причем одни варианты в парах могут различаться по значению, а другие - соотноситься как основной и допустимый, в ряде случаев действуют запретительные нормы.

С целью описания словарной фиксации ударения в данной группе слов, а также их функционирования в студенческом дискурсе нами были отобраны 15 контрольных лексем, имеющих различные акцентные структуры и принадлежащих к разным акцентным типам: сливовый, оптовый, минусовыци, митинговый, лозунговый, подростковый, бочковый, бредовый, вересковый, ворсовый, громовый, кирзовый, поисковый, лавровый, языковый.

Методика эксперимента включала два этапа. На первом, предшествовавшем опросу информантов, проводилась сравнительная проверка акцентологии указанных лексических единиц по авторитетным орфоэпическим словарям современного русского языка: «Большому орфоэпическому словарю русского языка» (Каленчук и др.), «Словарю ударений русского языка» (Резниченко), «Современному орфоэпическому словарю русского языка...» (Горбачевич). На втором этапе эксперимента проводился опрос информантов 


\section{МАТЕРИАЛЫ И СООБЩЕНИЯ}

(67 человек - студентов негуманитарных факультетов Ивановского государственного политехнического университета и Ивановского государственного химико-технологического университета) в возрасте от 17 до 20 лет.

\section{Экспериментальная часть: данные словарей}

С целью выявления всего многообразия существующих акцентных вариантов контрольных лексем мы обратились к трем вышеуказанным словарям. Они имеют своей целью «объективное фиксирование явлений, отражающих динамику языкового развития. Авторы современных орфоэпических словарей стремятся к более полному описанию особенностей ударения наших дней» [Здорикова, 2014, с. 28]. Например, в «Большом орфоэпическом словаре русского языка» фиксируется «реальное многообразие сосуществующих в литературной речи вариантов произношения и ударения», «в качестве рекомендуемых норм приведены в первую очередь те варианты произношения, которые освящены традицией русского литературного языка как языка культуры, а из новых произносительных явлений отобраны те, которые не только достаточно широко распространены, но и отвечают внутренним тенденциям языкового развития» [Каленчук, Касаткин, Касаткина, 2012, с. 3].

По мнению ученых, акцентные нормы в русском языке относятся к наиболее неустойчивым, что объясняется достаточно низкой, по сравнению с сегментными средствами, их фонологической значимостью [Трофимова, 2013, с. 72]. Действительно, по сравнению, например, с английским языком, в русском ударение нефиксированное, свободное, а значит подвижное, хотя в обоих языках акцентуация в пределах фонематического слова носит динамический (силовой) характер. Для установления нормативности того или иного акцентного варианта необходимо тем не менее обращаться к лексикографическим источникам.

15 контрольных лексем (8 трехсложных и 7 четырехсложных структур с вариативными акцентными типами), послуживших материалом для исследования, представляют собой лексические единицы, в которых наблюдается акцентная вариативность, отмеченная не менее чем двумя источниками. При отборе учитывались все типы вариативности: акцентная структура и акцентный тип слова, равнозначные и допустимые варианты, а также устаревшие, устаревающие, нерекомендуемые, неправильные акцентные формы. Принимая во внимание невысокий фонологический статус словесного ударения в русском языке [Трофимова, 2013, с. 72], допускающий вариативность, можно предположить, что по акцентной характеристике будут совпадать слова в тех лексикографических источниках, которые менее отдалены друг от друга по времени издания. В таблице 1 систематизирован собранный экспериментальный материал, по-разному отражающий колебания в системе русского словесного ударения на современном этапе.

\section{Выводы}

Приведенные в таблице данные свидетельствуют о широкой вариативности акцентных типов слова и, следовательно, о подвижности акцентной нормы. В ряде случаев наблюдается наличие вариантов той или иной лексемы в одном или двух словарях и отсутствие в другом: митинговый, лозунговый, подростковый, ворсовый (-ой), поисковый. По ряду акцентных вариантов обнаруживается полное совпадение: сли́вовый, опто́вый, ве́ресковый, ла́вровый и лавро́вый, языково́й и языко́вый (в двух последних парах слов, представленных в таблице, разные акцентные типы выполняют дистинктивную функцию по семантическому признаку).

При общем совпадении пар акцентных вариантов, например, по слову минусовый, один из словарей фиксирует варианты ми́нусовый и минусо́вый, которые соотносятся как основной и допустимый (Горбачевич, с. 165). В одном из лексикографических источников фиксируются как правомерные оба акцентных типа слова лозунговый (Резниченко, с. 318), а в другом - вариант ло́зунговый выступает как единственно возможный, а вариант лозунго́вый приводится с запретительной пометой (Горбачевич, с. 155).

Встречаются случаи разновариантных основных акцентных типов слов (бочково́й и бо́чковый). Наблюдаются и стилистичес- 
Вариативность акцентной нормы словесного ударения (по материалам орфоэпических словарей современного русского литературного языка)

\begin{tabular}{|c|c|c|}
\hline $\begin{array}{c}\text { Большой орфоэпический словарь рус- } \\
\text { ского языка. Литературное } \\
\text { произношение и ударение начала } \\
\text { XXI в.: норма и ее варианты } \\
\end{array}$ & $\begin{array}{c}\text { Словарь ударений русского } \\
\text { языка }\end{array}$ & $\begin{array}{c}\text { Современный орфоэпический } \\
\text { словарь русского зыка. } \\
\text { Все трудности произношения и ударения }\end{array}$ \\
\hline Сли́вовыцй (!не рек. сливо́вый) & Сли́вовый & Сли́вовый (!не рек. сливо́вый) \\
\hline Onто́вый (!неправ. о́птовый) & $\begin{array}{l}\text { Onmóвый. «Неудивительно, если } \\
\text { вы произносите данное слово } \\
\text { по-иному. Норма ударения в } \\
\text { нем изменялась, и в старинных } \\
\text { словарях можно встретить даже } \\
\text { оптовой». }\end{array}$ & Onто́выц̆ (!неправ. ónтовый) \\
\hline Ми́нусовыцй и минусо́вый & Ми́нусовыцй и минусо́вый & Мйнусовый (!допуст. минусо́вый) \\
\hline Слово отсутствует & Митинго́вый & $\begin{array}{l}\text { Митинго́вый (!устаревающ. } \\
\text { ми́тинговый) }\end{array}$ \\
\hline Слово отсутствует & Ло́зунговый и лозунго́вый & Ло́зунговый (!не рек. лозунго́вый) \\
\hline Слово отсутствует & Подро́стковыцй и подростко́выц й & Подро́стковый (!допуст. подростко́вылй) \\
\hline Бочково́й (!допуст. бо́чковый) & Бо́чковьй & Бо́чковый (!допуст. бочково́й) \\
\hline Бредо́выцй (!у медиков бредово́й) & Бредово́й и бредо́вы й & Бредо́вый (!допуст. бредово́й) \\
\hline Ве́ресковыцй (!не рек. вереско́вый) & Ве́ресковый & Ве́ресковый (!не рек. вереско́вый) \\
\hline $\begin{array}{l}\text { Во́рсовый и ворсово́й } \\
\text { (!не рек. ворсо́выц й) }\end{array}$ & Ворсово́й и во́рсовый & Слово отсутствует \\
\hline Громово́й (!допуст. старш. громо́вый) & Громово́й и громо́вый & Громово́й (!устарелое громо́вый) \\
\hline Кирзо́вый (!допуст ки́рзовый) & Ки́рзовый и кирзо́вый & Ки́рзовыцй (!допуст кирзо́выıи) \\
\hline Слово отсутствует & По́исковый и поиско́вый & Поиско́вый (!устаревающ. по́исковый) \\
\hline Ла́вровый и лавро́вый & Ла́вровый и лавро́вый & Ла́вровый (рощса) и лавро́вый (лист) \\
\hline Языково́й и языко́вый & Язылково́й и язылко́выцй & Язылково́й (речь) и язылко́выцй (колбаса) \\
\hline
\end{tabular}

кие акцентные типы: бредово́й (!у медиков) и бредо́вый. Ряд вариантов имеет помету «устарелый»: громо́вый, в то время как вариант ми́тинговыцй имеет обозначение «устаревающий», демонстрируя динамику нормы (Горбачевич, с. 166). Многие лексемы приводятся с запретительными пометами: сливо́вый, о́птовый, лозунго́вый, вереско́вый, ворсо́вый.

Следует отметить, что в двух лексикографических источниках (Горбачевич; Каленчук и др.) приводится большая градация вариантов акцентных типов. По-видимому, наблюдаемая широкая вариативность акцентной нормы не в последнюю очередь обусловлена свободным характером словесного ударения в современном русском языке.

Экспериментальная часть:

\section{результаты анкетирования студентов}

На втором этапе эксперимента 15 лексем были предъявлены 67 информантам для акцентологического анализа, результаты которого представлены в таблице 2.

\section{Выводы}

Проведенный в студенческой среде эксперимент свидетельствует о еще большей вариативности функционирования акцентных типов указанных лексем, о существовании как нормативных реализаций, так и маргинальных акцентных вариантов. У некоторой части студентов вызвала затруднение акцентуация в ряде лексем (сливовый, громовый), либо не была отмечена вовсе (вересковый, ворсовый, кирзовый). Маргинальные реализации типа языкувой, язымковый и др. следует рассматривать в рамках статистической погрешности.

\section{Заключение}

Выявленная в ходе исследования акцентной нормы русских прилагательных на -овыцй тенденция к вариативности подтверждает тезис о динамическом, развивающемся характере языковой системы. При этом вариативность акцентных структур предоставляет говорящему большие возможности выбора той или иной произносительной модели, что мо- 


\section{Результаты функционирования акцентных типов 15 контрольных лексем на -овый в дискурсе студентов}

\begin{tabular}{|c|c|}
\hline $\begin{array}{c}\text { Контрольные } \\
\text { лексемы }\end{array}$ & Результаты анкетирования студентов \\
\hline сливовыци & сли́вовыци 53, сливо́вый 13, затрудн. 1 \\
\hline оптовыц й & о́птовый 19, опто́вый 47, оптовыц́u 1 \\
\hline минусовый & ми́нусовый 18, минусо́вый 42, оба вар. 7 \\
\hline митинговый & ми́тинговый 55, митинго́вый 11, мити́нговый 1 \\
\hline лозунговый & ло́зунговый 53, лозунго́вый 13, льозулиговый 1 \\
\hline подростковый & подро́стковый 36, подростко́вый 33 \\
\hline бочковой & бочково́й 4, бо́чковый 50, бочко́вый 13 \\
\hline бредовый & бредово́й 2, бредо́вый $\mathbf{6 2}$, бре́довый $\mathbf{3}$ \\
\hline вересковый & ве́ресковый 41, вереско́вый 20, вере́сковый $\mathbf{5}$, затрудн. 1 \\
\hline ворсовыц̆ & во́рсовый 58, ворсо́вый 11 \\
\hline громовой & громово́й 28, громо́вый 10, гро́мовый 27, затрудн. $\mathbf{2}$ \\
\hline кирзовыц̆ & ки́рзовый 50, кирзо́вый 17 \\
\hline поисковый & по́исковый 35, поиско́вый 31, пои́сковый 1 \\
\hline лавровый & $\begin{array}{l}\text { ла́вровый: рощуа 11, чащза 1, почести 2, растительность } \mathbf{2}, \text { венок } \mathbf{6}, \\
\text { лавро́вый: лист } \mathbf{6 3}, \text { венок } \mathbf{1}, \text { продукт } \mathbf{1}\end{array}$ \\
\hline языковой & 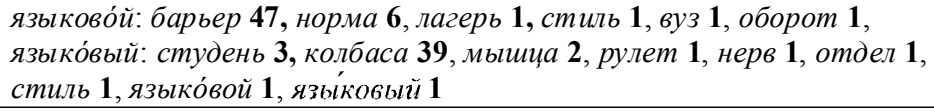 \\
\hline
\end{tabular}

жет стать весьма релевантным в дальнейшем для кодификации в лексикографических источниках новых вариантов акцентной нормы слов в русском языке (в данном случае прилагательных на -овый).

Из анализа полученных экспериментальных данных следует, что большинство студентов высших учебных заведений соблюдают нормы акцентуации в русских прилагательных на -овый, выбирая либо основной, либо допустимый акцентные варианты.

\section{СПИСОК ЛИТЕРАТУРЫ}

Вербицкая Л. А., 2001. Давайте говорить правильно. М. : Высшая школа. 239 с.

Вишневская Г. М., Абызов А. А., 2016. Канадский языковой разлом (англо-французский билингвизм). Иваново : ИВГПУ. 200 с.

Встречи с Костомаровым..., 2015. Встречи с Костомаровым. К юбилею русиста: ученого, педагога, учителя : Избранные выступления и интервью В.Г. Костомарова, основателя и Президента Государственного института русского языка им. А.С. Пушкина. М. : Гос. ин-т рус. яз. им. А.С. Пушкина. 76 с.

Горбачевич К. С., 1978. Вариантность слова и языковая норма. Л. : Наука. 240 с.

Едличка А., 1976. Проблематика нормы и кодификации литературного языка в отношении к типу литературного языка // Проблемы нор- мы в славянских литературных языках в синхронном и диахронном аспектах : докл. на IV заседании Междунар. комис. по слав. лит. яз. / под. ред. чл.-кор. АН СССР Ф.П. Филина и проф. А.И. Горшкова. М. : Наука. С. 16-39.

Здорикова Ю. Н., 2014. Вариативность современной орфоэпической системы русского языка и кодификация // Вестник гуманитарного факультета Ивановского государственного химикотехнологического университета. № 6. С. 27-30.

Каленчук М. Л., Касаткин Л. Л., Касаткина Р. Ф., 2012. От авторов // Большой орфоэпический словарь русского языка. Литературное произношение и ударение начала XXI века: норма и ее варианты / под ред. Л. Л. Касаткина. М. : АСТ-ПРЕСС КНИГА. С. 3.

Костомаров В. Г., 2014. Язык текущего момента: понятие правильности. СПб. : Златоуст. 220 с.

Левина Т. В., 2003. Эволюционные процессы в орфоэпической норме современного английского языка. Владимир : Изд-во ВГПУ. 125 с.

Петрова Т. А., 2013. Вариативность нормы как способность к сохранению актуальности языковой единицы // Естественно-гуманитарные исследования. № 1. С. 84-88.

Скворцов Л. И., 1980. Теоретические основы культуры речи. М. : Наука. 352 с.

Солнцев В. М., 1984. Вариативность как общее свойство языковой системы // Вопросы языкознания. № 2. С. 31-42.

Торсуев Г. П., 1960. Вопросы акцентологии современного английского языка. М. ; Л. : АН CCCP. 92 c. 
Торсуев Г. П., 1977. Константность и вариативность в фонетической системе. М. : Наука. 125 с.

Трофимова Е. Б., 2013. Пространство нормы словесного акцента в русском языке // Мир лингвистики и коммуникации. № 4 (33). С. $72-83$.

Шахбагова Д. А., 1992. Фонетическая система в диахронии и синхронии (на материале британского, американского, австралийского, канадского вариантов английского языка). М. : Фоллис. 284 с.

Vishnevskaya G. M., 2000. Phonetic Variation, the Pronunciation Norm of English and the Russian Learner // Фонетическая вариативность: билингвизм и диглоссия : Межвуз. сб. науч. тр. Иваново : Иван. гос. ун-т. С. 67-73.

\section{СЛОВАРИ}

Горбачевич - Горбачевич К. С. Современный орфоэпический словарь русского языка. Все трудности произношения и ударения: ок. 12000 заголовочных единиц. М. : Астрель : ACT, 2010. $476 \mathrm{c}$.

Каленчук и др. - Каленчук М. Л., Касаткин Л. Л., Касаткина Р. Ф. Большой орфоэпический словарь русского языка. Литературное произношение и ударение начала XXI века: норма и ее варианты. М. : АСТ-ПРЕСС КНИГА, 2012. 1008 c.

Орфоэпический словарь - Орфоэпический словарь русского языка: Произношение, ударение, грамматические формы / под ред. Р. И. Аванесова. Изд. 3-е. М. : Русский язык, 1987. 704 с.

Резниченко - Резниченко И. Л. Словарь ударений русского языка. М. : АСТ-ПРЕСС КНИГА, 2008.944 c.

\section{REFERENCES}

Verbitskaya L.A., 2001. Let's talk correctly. Moscow, Vysshaya shkola Publ. 239 p.

Vishnevskaya G.M., Abyzov A.A., 2016. Canadian language rift (Anglo-French bilingualism). Ivanovo, IVGPU Publ. $200 \mathrm{p}$.

Meetings with Kostomarov. To the jubilee of a specialist in Russian philology: a scholar and a teacher. Selected speeches and interviews of V.G. Kostomarov, founder and President of the State Institute of Russian Language named after A.S. Pushkin. Moscow, Izd-vo gos. un-ta russ. yazyka im. A.S. Pushkina, 2015. 76 p.

Gorbachevich K.S., 1978. Word variation and the language norm. Leningrad, Nauka Publ. 240 p.
Edlichka A., 1976. Problems of the norm and codification of the literary language in relation to its type. Gorshkov A.I., ed. Problemy normy $v$ slavyanskikh literaturnykh yazykakh $v$ sinkhronnom $i$ diakhronnom aspektakh: Dokl. na IV zasedanii Mezhdunar. komis. po slav. lit. yaz. Moscow, Nauka Publ., pp. 16-39.

Zdorikova Yu.N., 2014. Variability of modern Russian orthoepic system and codification. Vestnik gumanitarnogo fakulteta Ivanovskogo gosudarstvennogo khimikotekhnologicheskogo universiteta, no. 6, pp. 27-30.

Kalenchuk M.L., Kasatkin L.L., Kasatkina R.F., 2012. Authors' word. Big orthoepic dictionary of the Russian language. Literary pronunciation and stress of the beginning of the $21^{\text {st }}$ century: the norm and its alternants. Moscow, AST-PRESS Publ. p. 3.

Kostomarov V.G., 2014. The language of the current moment: the concept of correctness. Saint Petersburg, Zlatoust Publ. 220 p.

Levina T.V., 2003. Evolutionary processes in the orthoepic norm of modern English. Vladimir, VGPU Publ. $125 \mathrm{p}$.

Petrova T.A., 2013. The variance of the norm as the ability to maintain the relevance of language unit. Estestvenno-gumanitarnye issledovaniya, no. 1, pp. 84-88.

Skvortsov L.I., 1980. Theoretical basics of speech culture. Moscow, Nauka Publ. 352 p.

Solntsev V.M., 1984. Variation as a general property of the language system. Voprosy yazykoznaniya [Topics in the Study of Language], no. 2, pp. 31-42.

Torsuev G.P., 1960. Questions of the accentology of modern English. Moscow; Leningrad, AN SSSR Publ. 92 p.

Torsuev G.P., 1977. Consistency and variation in the phonetic system. Moscow, Nauka Publ. $125 \mathrm{p}$.

Trofimova E.B., 2013. The sphere of the Russian stress norm. Mir lingvistiki i kommunikatsii [World of Linguistics and Communication], no. 4 (33), pp. 72-83.

Shakhbagova D.A., 1992. Phonetic system in diachrony and synchrony (on the material of the British, American, Australian, Canadian variants of the English language). Moscow, Follis Publ. 284 p.

Vishnevskaya G.M., 2000. Phonetic variation, the pronunciation norm of English and the Russian learner. Foneticheskaya variativnost: bilingvizm i diglossiya. Mezhuvuz. sb. nauch. tr. Ivanovo, Izd-vo IGU, pp. 67-73. 


\section{МАТЕРИАЛЫ И СООБЩЕНИЯ}

\section{DICTIONARIES}

Gorbachevich K.S., 2010. Modern prononciation dictionary of the Russian language. All difficulties of pronunciation and stress: approx. 12,000 head words. Moscow, Astrel Publ. 476 p.

Kalenchuk M.L., Kasatkin L.L., Kasatkina R.F., 2012.

Big orthoepic dictionary of the Russian language. Literary pronunciation and stress of the beginning of the $21^{\text {st }}$ century: the norm and its alternants. Moscow, AST-PRESS Publ. $1008 \mathrm{p}$.

Avanesov R.I., ed., 1987. Orthoepic Dictionary of the Russian language: Pronunciation, stress, grammatical forms. Moscow, Russkiy yazyk Publ. 704 p.

Reznichenko I.L., 2008. Dictionary of accents of the Russian language. Moscow, AST-PRESS Publ. $944 \mathrm{p}$.

\section{Information about the Authors}

Aleksey A. Abyzov, Candidate of Sciences (Philology), Associate Professor, Department of Foreign Languages, Ivanovo State Polytechnic University, 8 Marta St., 20, 153037 Ivanovo, Russia, axxel68@mail.ru, https://orcid.org/0000-0002-0691-8184

Yuliya N. Zdorikova, Candidate of Sciences (Philology), Associate Professor, Department of the Russian Language, Ivanovo State University of Chemistry and Technology, Prosp. Sheremetevskiy, 7, 153000 Ivanovo, Russia, ulia_zdor@mail.ru, https://orcid.org/0000-0001-6124-8251

\section{Информация об авторах}

Алексей Алексеевич Абызов, кандидат филологических наук, доцент, доцент кафедры иностранных языков, Ивановский государственный политехнический университет, ул. 8 Марта, 20, 153037 г. Иваново, Россия, axxel68@mail.ru, https://orcid.org/0000-0002-0691-8184

Юлия Николаевна Здорикова, кандидат филологических наук, доцент, доцент кафедры русского языка, Ивановский государственный химико-технологический университет, просп. Шереметевский, 7, 153000 г. Иваново, Россия, ulia_zdor@mail.ru, https://orcid.org/0000-0001-6124-8251 